\title{
Article \\ The Effects of Prior Austenite Grain Refinement on Strength and Toughness of High-Strength Low-Alloy Steel
}

\author{
Xiucheng Li ${ }^{1, *(\mathbb{D})}$, Guangyi Lu ${ }^{1}$, Qichen Wang ${ }^{2}$, Jingxiao Zhao ${ }^{1}$, Zhenjia Xie ${ }^{1}{ }^{(\mathbb{D}}$, Raja Devesh Kumar Misra ${ }^{3, *}$ \\ and Chengjia Shang $1,4, *$ \\ 1 Collaborative Innovation Center of Steel Technology, University of Science and Technology Beijing, \\ 30 Xueyuan Road, Haidian District, Beijing 100083, China; lu13012436630@163.com (G.L.); \\ zhjingxiao@yeah.net (J.Z.); zjxie@ustb.edu.cn (Z.X.) \\ 2 CIMC Offshore Engineering Institute Company Ltd., 33 Keji Road, Gaoxin District, Yantai 264670, China; \\ qichen.wang@cimc-raffles.com \\ 3 Department of Metallurgical, Materials and Biomedical Engineering, University of Texas at El Paso, \\ 500 W. University Avenue, El Paso, TX 79968, USA \\ 4 Yantai Institute of Industrial Technology, University of Science and Technology Beijing, 117 Shanhai South Road, \\ Laishan District, Yantai 264003, China \\ * Correspondence: xcli_ustb@163.com (X.L.); dmisra2@utep.edu (R.D.K.M.); cjshang@ustb.edu.cn (C.S.)
}

\section{check for} updates

Citation: Li, X.; Lu, G.; Wang, Q.; Zhao, J.; Xie, Z.; Misra, R.D.K.; Shang, C. The Effects of Prior Austenite Grain Refinement on Strength and Toughness of High-Strength Low-Alloy Steel. Metals 2022, 12, 28. https://doi.org/ $10.3390 /$ met12010028

Academic Editors:

Carlos Garcia-Mateo, Xueda Li and Xiangliang Wan

Received: 28 November 2021 Accepted: 16 December 2021

Published: 24 December 2021

Publisher's Note: MDPI stays neutral with regard to jurisdictional claims in published maps and institutional affiliations.

Copyright: (c) 2021 by the authors. Licensee MDPI, Basel, Switzerland. This article is an open access article distributed under the terms and conditions of the Creative Commons Attribution (CC BY) license (https:// creativecommons.org/licenses/by/ $4.0 /)$.

\begin{abstract}
The effects of prior austenite grain (PAG) refinement on the mechanical properties of bainitic/martensitic steels not only come from itself, but also have more complex effects by affecting the substructure formed by coherent transformation. In this study, the samples of a low-alloy steel were water quenched from different austenitizing temperatures and the bainitic/martensitic microstructures with different PAG sizes were obtained. Electron back-scattered diffraction was used to characterize the microstructure and different types of boundaries were identified and quantitatively analyzed. The tensile tests and series temperature Charpy impact tests of different heat treatment were also carried out and comprehensively analyzed with microstructure characterization works. The results show that the uniform refinement of prior austenite grain can increases the density of packet boundary and block boundary, which leads to microstructure refinement with higher density of highangle grain boundaries with misorientation $>45^{\circ}$. The contribution of this microstructure refinement to toughness is significant, but its contributions to strength and elongation are relatively limited. Compared to uniform refined PAG, if the PAGs are mixed crystal, the density of block boundary will be reduced, which leads to a lower density of the high-angle boundary with misorientation $>45^{\circ}$ and the positive effects of microstructure refinement on toughness improvement are weakened. The observation of fracture surface of impact specimens indicates that refining the PAG can delay the tendency of brittle fracture with the decrease in test temperature, and even in the case of brittle fracture, the cleavage facet of the fracture surface is relatively smaller. This result also verifies that PAG refinement can effectively improve toughness by inhibiting cleavage fracture.
\end{abstract}

Keywords: bainitic/martensitic steel; prior austenite grain; boundary; strength; toughness

\section{Introduction}

It is well known that the strength and toughness of iron and steel materials can be simultaneously improved by grain refinement. However, for most low-alloy highstrength steels, whose microstructure is bainite or martensite, the concept of grain is more complicated, because bainite/martensite has multi-level crystallographic structures. Grain in bainite/martensite can be prior austenite grain (PAG), packet, block/sub-block or lath [1]. There is a hierarchical relationship among these crystallographic units. A PAG is divided to several packets, which are a group of laths with almost same habit plane. A packet is sub-divided by blocks which contain a group of laths. Lath is the smallest crystal unit which has almost the same orientation. 
The refinement of PAG is considered as the first step to realize the microstructure refinement of bainitic/martensitic steels. On one hand, as mentioned above, PAG is the highest-level crystal unit in bainite/martensite microstructure and other crystal units, i.e., packet, block and lath are the sub-units. If PAG is well refined, the upper limit of the size of other crystal units is reduced. On the other hand, previous studies have shown PAG boundaries always have higher misorientation of slip plane and also cleavage plane [2]; thus, they are more effective in governing dislocation pile up and inhibiting cleavage fracture [3]. There are also a large number of research results showing that the refinement of prior austenite grain is beneficial to both of strength and toughness of steel. However, in some special cases, the effects of PAG refinement on strengthening and toughening are not so obvious as it expects, even there are some counter-examples [4]. Of course, any phenomenon has scientific principles which lead to its occurrence. Therefore, more detailed and comprehensive microstructure analysis methods are still needed to help us deeply understand these seemingly abnormal phenomena and improve steel manufacturing process.

Electron back-scattered diffraction (EBSD) is a powerful technique which can give detailed crystallographic information of microstructure in a large observation area $[5,6]$, and it has been used to realize the rapid identification and quantitative statistics of all interfaces in bainitic/martensitic microstructure with a decent accuracy [7]. This study attempts to use quantitative analysis method of boundaries to investigate the effects of PAG refinement on mechanical properties, and the mixed crystal condition of PAG [8] is also paid special attention.

\section{Materials and Methods}

The chemical composition of the experimental steel in weight percentage is $0.12 \% \mathrm{C}$, $0.20 \% \mathrm{Si}, 1.20 \% \mathrm{Mn}, 0.50 \% \mathrm{Cr}, 1.00 \% \mathrm{Ni}, 0.65 \% \mathrm{Mo}, 0.015 \% \mathrm{Ti}, 0.0015 \% \mathrm{~B}, 0.008 \% \mathrm{P}, 0.004 \% \mathrm{~S}$ and balance Fe. Steel blanks, whose size is $150 \mathrm{~mm}$ (longitudinal) $\times 120 \mathrm{~mm}$ (transversal) $\times 40 \mathrm{~mm}$ (thickness), were cut from a $40 \mathrm{~mm}$ thick hot rolled plate and reheated to temperatures of $850{ }^{\circ} \mathrm{C}, 950{ }^{\circ} \mathrm{C}$ and $1050{ }^{\circ} \mathrm{C}$, respectively, held for $30 \mathrm{~min}$, water quenched. The samples corresponding to different austenitizing temperatures are referred henceforth as Q850, Q950 and Q1050. The specimens for tensile test and Charpy V-notch impact toughness test were prepared from the quarter-thickness of the plate. Dog-bone-bar-shaped (effective tested zone: $\Phi 5 \mathrm{~mm} \times 25 \mathrm{~mm}$ ) tensile specimens were tested at room temperature and at a strain rate of $1.0 \times 10^{-3} / \mathrm{s}$ according to GB/T 228.1-2010, which is in duplicate. Standard V-notched Charpy impact specimens $(10 \mathrm{~mm} \times 10 \mathrm{~mm} \times 55 \mathrm{~mm})$ were tested at room temperature, $-20^{\circ} \mathrm{C},-40{ }^{\circ} \mathrm{C}$ and $-60{ }^{\circ} \mathrm{C}$ separately according to GB/T 229-2020, which is in triplicate. The specimens were cooled in the low-temperature tank of impact test, and the test was carried out after the specimens reached the set temperature for two minutes. In order to study the fracture characteristics of all samples when cleavage fracture occurs, one extra Charpy impact specimen of each sample was tested at $-120{ }^{\circ} \mathrm{C}$.

Scanning electron microscopy (SEM, TESCAN MAIA3, TESCAN ORSAY HOLDING, Brno-Kohoutovice, Czech Republic) equipped with EBSD (Oxford Instruments) was used for microstructure characterization. Step size was set at $0.15 \mu \mathrm{m}$, which is much smaller than the variant size of all the samples. The EBSD data were interpreted using the HKL technology Channel 5 software (Ver. 5.12.72.0, Oxford Instruments, Oxford, UK). A selfwritten Python script was also employed to classify and quantify the boundaries [7]. The fracture surface of some impact specimens was observed by SEM.

\section{Results}

Figure 1 shows the interpreted result of EBSD measurement with HKL technology Channel 5 software. Figure $1 \mathrm{a}-\mathrm{c}$ are the band contrast maps which can reflect the interfaces distribution within the microstructure. Obviously, the microstructures of the three samples are lath structure, which can be lath bainite or lath martensite. The microstructure of Q850 seems to be more refined. Some of the laths in Q850 are very short, and some are 
as long as the laths in Q950. Q1050 samples have the longest laths among three samples. Figure $1 \mathrm{~d}-\mathrm{f}$ are the inverse pole figure color maps, in which different colors represent the crystallographic units of bainite/martensite that agree with the orientation perpendicular to the observed plane, as indicated by the stereographic triangle in the inset. To a great extent, inverse pole figure map reflects the grains with different crystallographic orientations. It is not hard to find Q850 also has the finest structure and Q1050 has coarsest structure from the view of crystal misorientation. Misorientation angle is an important parameter which can evaluate the effect of different boundaries on toughness. High angle grain boundaries (HAGBs) can play a greater role in toughness improvement by forcing the crack to deviate. On HAGBs, different studies considered the misorientation angles of boundary should be greater than $15^{\circ}[9,10]$ or $45^{\circ}[11,12]$. In this study, the density of HAGBs $\left(>15^{\circ}\right)$ obviously decreases with the increase in austenitizing temperature. Q1050 also has the lowest density of HAGBs $\left(>45^{\circ}\right)$ and Q850 has the highest density, but the difference of density between Q850 and Q950 is very slight, as shown in Figure 2.
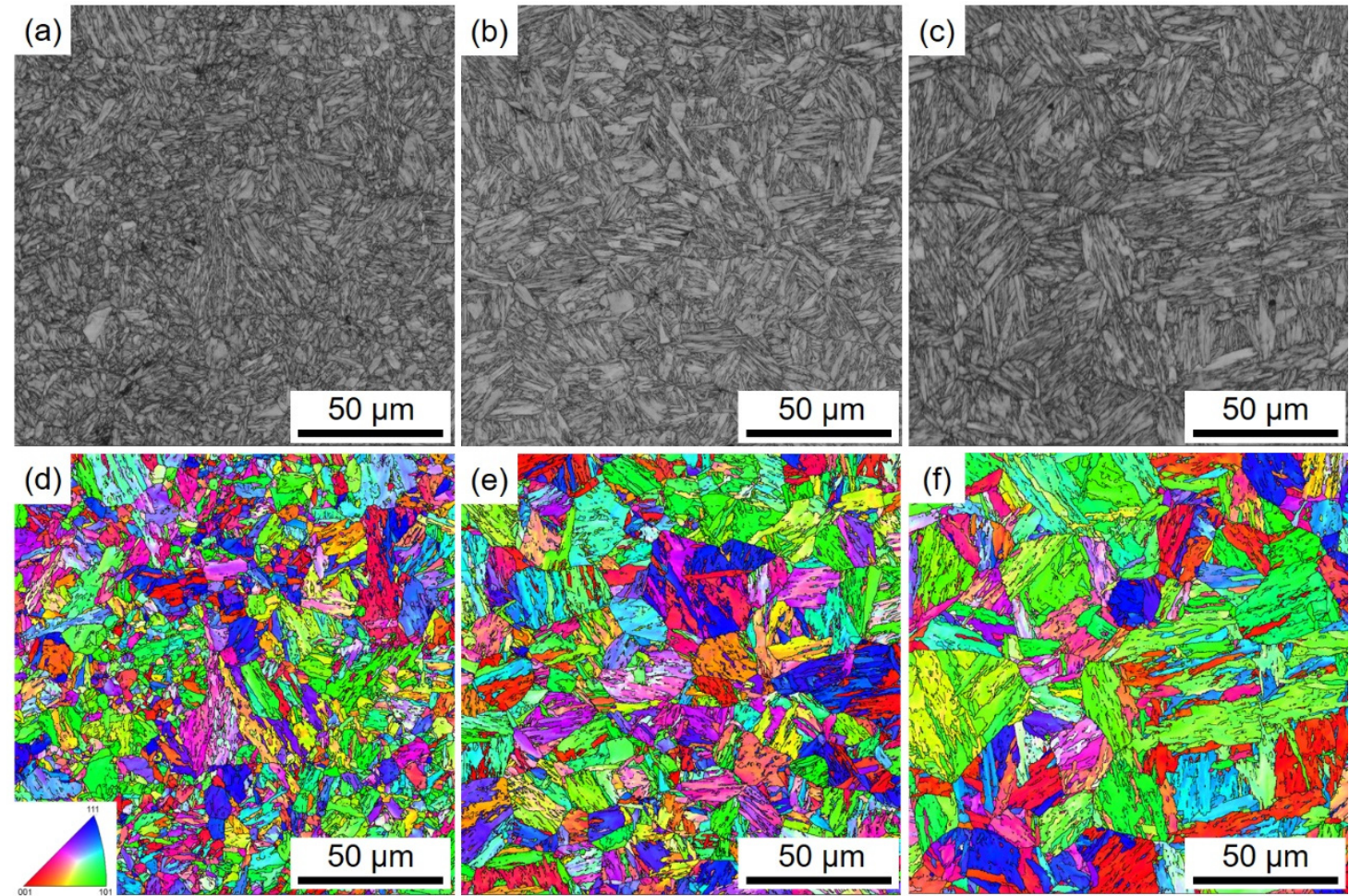

Figure 1. Band contrast map $(\mathbf{a}-\mathbf{c})$ and inverse pole figure color map $(\mathbf{d}-\mathbf{f})$ of three experimental samples: (a) and (d) Q850, (b) and (e) Q950, (c) and (f) Q1050.

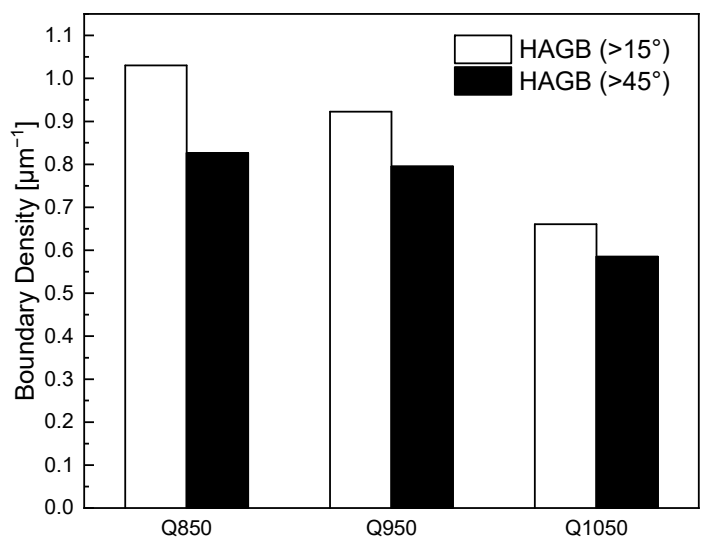

Figure 2. The density of HAGBs in three experimental samples. 
The classification and quantitative statistics of boundaries can reveal more detailed information on the microstructure. In Figure 3, different types of boundaries are marked with different colors. Through the quantitative statistics, it can be found that the densities of PAG boundary and block boundary decrease with the increase in austenitizing temperature, but more block boundaries are formed when the austenitizing temperature is $950{ }^{\circ} \mathrm{C}$, and there is almost no difference in sub-block boundary density between different experimental samples, as shown in Figure 4. When the PAG boundaries are drawn separately in Figure 5, it is easy to see the PAGs are also well refined by decreasing austenitizing temperature. Q850 has very fine PAGs, whose average diameter is $12.4 \pm 11.8 \mu \mathrm{m}$. It can be found Q850 has mixed crystal PAGs which leads to large standard deviation of grain size. This is because $850{ }^{\circ} \mathrm{C}$ is a temperature close to the starting of austenitization; thus, some PAGs nucleated but did not grow rapidly. The PAGs of Q950 are coarser than Q850, the average diameter is measured to be $18.1 \pm 9.0 \mu \mathrm{m}$, the PAG size of Q950 is also the most uniform one among three samples. The average diameter of PAGs of Q1050 is $25.3 \pm 15.4 \mu \mathrm{m}$, and it can be found there are some abnormal grown PAGs (Figure 5c). Some investigations considered this phenomenon to be related to the dissolution of precipitates at specific temperature range $[13,14]$. In brief, the refinement of PAGs leads to an increase in packet boundary density, but the influences on block boundary formation may be more complex if mixed crystal PAGs exist.
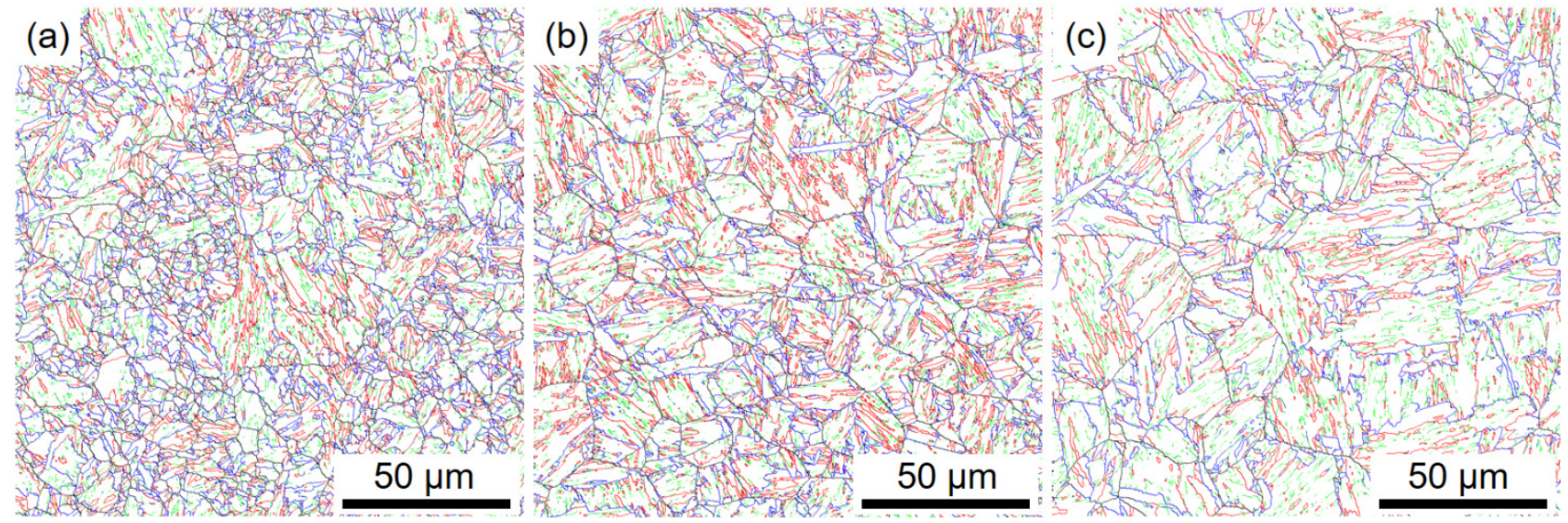

Figure 3. Different types of boundaries (black lines: PAG boundaries, blue lines: packet boundaries, red lines: block boundaries, green lines: sub-block boundaries) of (a) Q850, (b) Q950 and (c) Q1050.

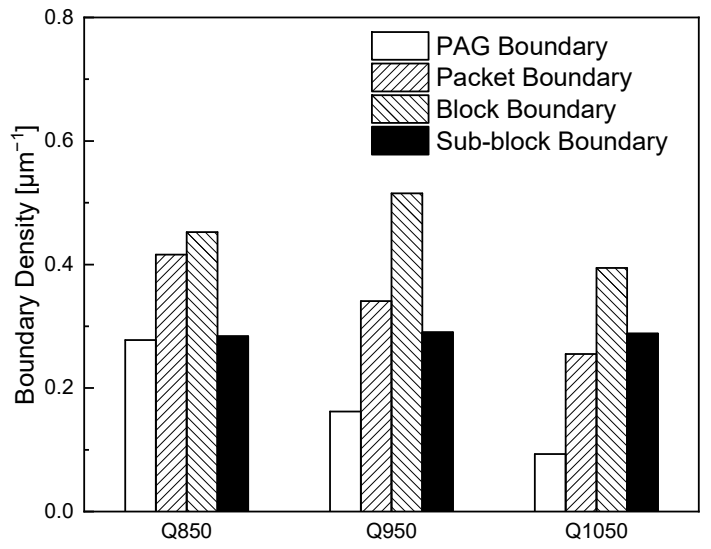

Figure 4. Comparison of density according to different grain boundary type. 

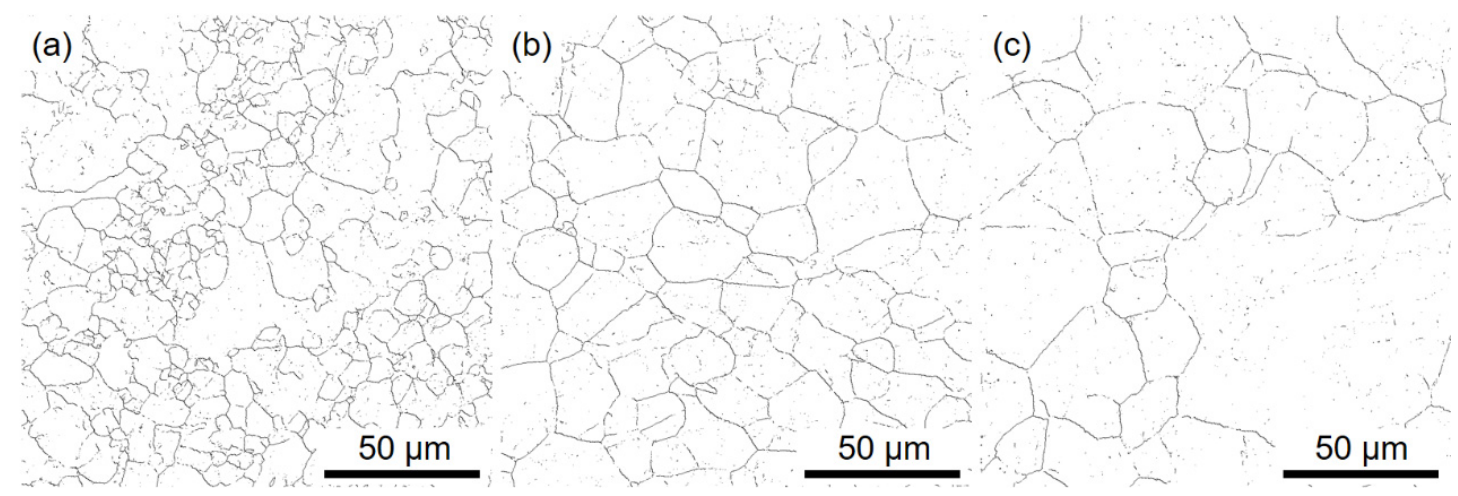

Figure 5. PAG boundary map of three experimental samples: (a) Q850, (b) Q950 and (c) Q1050.

The results of tensile tests are shown in Table 1. Q850 has the highest yield strength, Q950 and Q1050 have similar yield strength which is 40 MPa lower than Q850. The tensile strength decreases by $\sim 20 \mathrm{MPa}$ in order of Q850, Q1050 and Q950. However, considering the strength grade of experimental steel is very high, this difference in strength can be almost ignored. Similarly, there are also no significant differences in uniform elongation, total elongation and fracture area reduction, though these parameters slightly decrease with the increase in austenitizing temperature.

Table 1. Tensile properties of experimental samples with different austenitizing temperatures.

\begin{tabular}{cccccc}
\hline Samples & $\begin{array}{c}\text { Yield Strength } \\
\text { (MPa) }\end{array}$ & $\begin{array}{c}\text { Tensile Strength } \\
\mathbf{( M P a )}\end{array}$ & $\begin{array}{c}\text { Uniform Elongation } \\
\mathbf{( \% )}\end{array}$ & $\begin{array}{c}\text { Total Elongation } \\
\mathbf{( \% )}\end{array}$ & $\begin{array}{c}\text { Reduction } \\
\mathbf{( \% )}\end{array}$ \\
\hline Q850 & $934 \pm 1$ & $1280 \pm 3$ & $4.1 \pm 0.1$ & $14.9 \pm 0.3$ & $68 \pm 2$ \\
Q950 & $893 \pm 5$ & $1243 \pm 9$ & $4.0 \pm 0.1$ & $14.5 \pm 0.1$ & $67 \pm 2$ \\
Q1050 & $898 \pm 7$ & $1260 \pm 1$ & $3.9 \pm 0.1$ & $13.8 \pm 0.2$ & $67 \pm 1$ \\
\hline
\end{tabular}

Charpy impact tests were conducted at series temperature from $25^{\circ} \mathrm{C}$ (room temperature) to $-60{ }^{\circ} \mathrm{C}$, and the results are shown in Figure 6. With the decrease in test temperature, the impact energy of each experimental sample decreases, but there is no obvious ductile brittle transition process, which may be because the impact energy is not so high at room temperature for a steel with such high strength. The toughness performance of Q850 and Q950 are almost the same and both of them are much better than Q1050, which indicates the refinement of PAG and the resulting microstructure refinement has a positive effect on toughness improvement. The impact energies at low temperature $\left(-120^{\circ} \mathrm{C}\right)$ for three samples are $13 \mathrm{~J}$ (Q850), $9 \mathrm{~J}$ (Q950) and $7 \mathrm{~J}$ (Q1050), respectively.

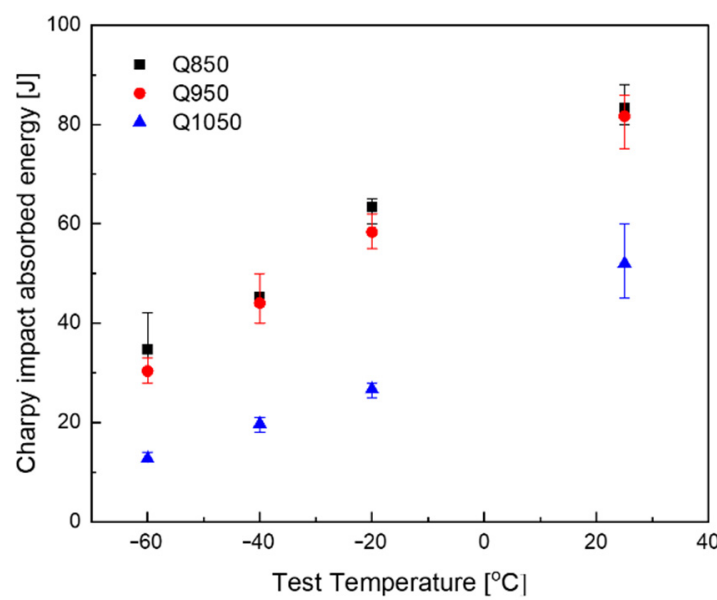

Figure 6. Charpy impact energy of experimental samples: (a) Q850, (b) Q950 and (c) Q1050. 


\section{Discussion}

There is no doubt that microstructure refinement is good for the mechanical properties of bainitic/martensitic steels. However, there are different viewpoints on what is the effective grain size which determines the strength or toughness. Different study attributes the effective grain size that affects the strength or toughness to packet $[4,15,16]$ or block $[17,18]$ and lath [19-21], respectively. In fact, so far, there is not a "crystallographic unit" which can be widely accepted has been found to define the effective grain size of bainite/martensite. It is also difficult to design a perfect experiment to investigate the contribution of the boundaries to strength and toughness, when other conditions, such as the concentration of solute atoms, dislocation density and precipitate state are all the same. Additionally, it is difficult to accurately characterize these parameters and evaluate their contributions to strength. In this study, from the results, it may say refinement of microstructure has little effect on strengthening because Q1050 also has similar yield strength and tensile strength with other two samples with finer microstructure. However, it can also be explained as that coarsen PAG of Q1050 sample leads to a higher martensite transformation temperature [22], thus stronger solid solution strengthening and dislocation strengthening can be formed. Therefore, the microstructure refinement may also have its nonnegligible influence on strengthening mechanism.

The complex hierarchy in crystallography of bainite/martensite makes the research more difficult. There are methods to identify bainite/martensite structure efficiently and accurately, and it has been known that the misorientation [23] or misorientation of specific crystallographic plane of boundary [24] has its own effect on strength or toughness, it is still hard to realize a quantitative analysis of the boundaries impact. On one hand, misorientation is important but not the only parameter determines the effects of boundaries itself on mechanical properties; and on the other hand, the distribution of boundaries is complex high-dimensional data, and it is difficult to build an effective analysis model. In this study, the Q850 sample has mixed crystal PAGs; thus, though it has higher density of HAGBs than Q950, they have the same toughness performance in a large test temperature range. Anyway, the refinement of microstructure with high density of HAGBs does improve the toughness generally, e.g., Q850 and Q950 have obviously better toughness than Q1050. An observation of fracture surface indicates that, at $-40{ }^{\circ} \mathrm{C}$, the crack initiation process of impact fracture of Q950 is plastic, and the crack propagation process also has a certain plasticity, as shown in Figure 7, while the whole fracture process of Q1050 at the same test temperature is almost completely brittle, as shown in Figure 8. When all three experimental samples are tested at a very low temperature and the fracture processes are all brittle, the facet area of cleavage fracture decreases significantly in Q850 sample, as shown in Figure 9, which imply the effect of microstructure refinement on cleavage maybe exist, even the PAGs are mixed crystal. Anyway, it is no doubt that a uniform refinement of PAGs is more welcomed because it can lead to higher density of packet boundary, block boundary, HAGB and so as to obtain better toughness performance.
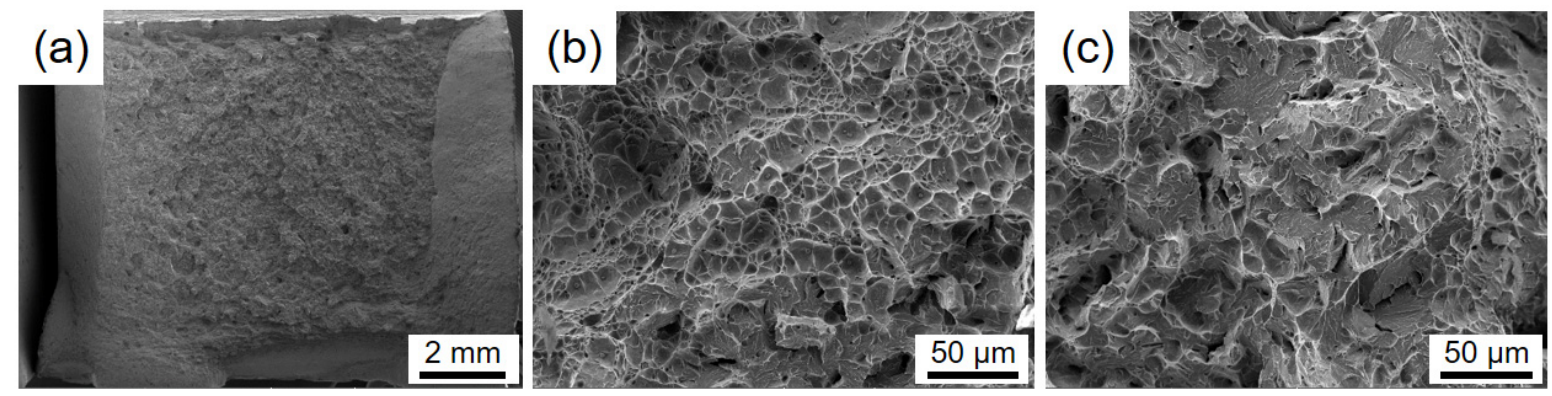

Figure 7. Morphology of fracture surface of Q950 impact tested specimen. (a) overall macromorphology of fracture surface, (b) micro-morphology of fracture surface close to the notch, (c) micro-morphology of fracture surface at the center. 

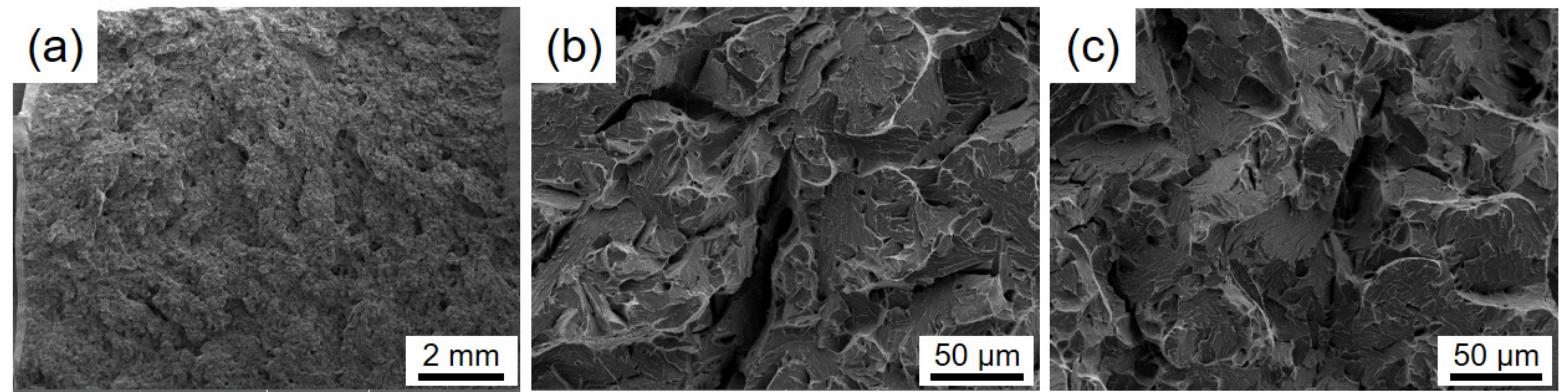

Figure 8. Morphology of fracture surface of Q1050 impact tested specimen. (a) overall macromorphology of fracture surface, (b) micro-morphology of fracture surface close to the notch, (c) micro-morphology of fracture surface at the center.
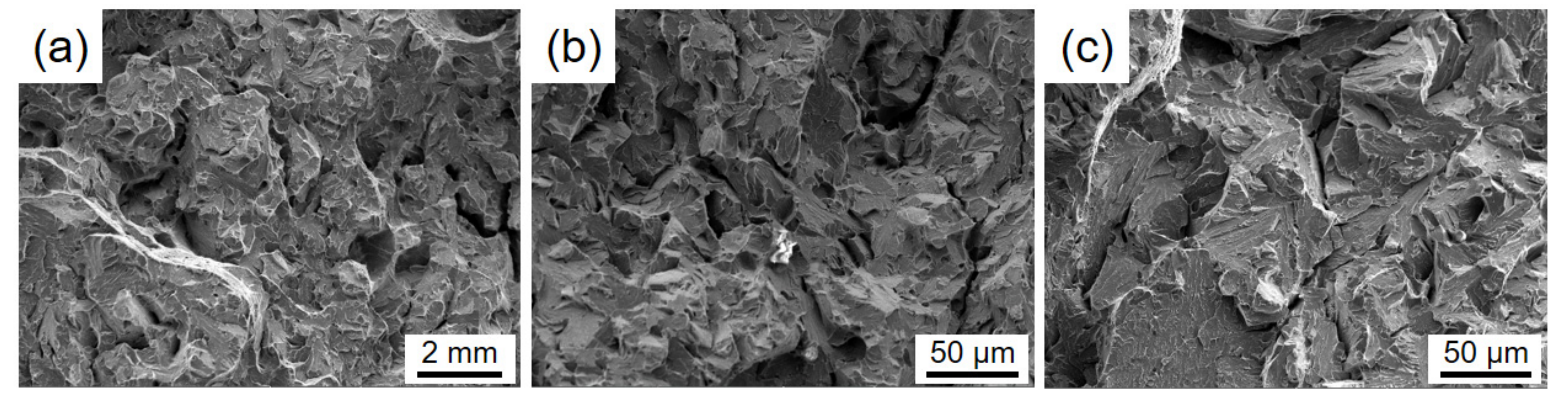

Figure 9. Micro-morphology of fracture surface of three experimental samples impact tested at $-120{ }^{\circ} \mathrm{C}$ : (a) Q850, (b) Q950 and (c) Q1050.

\section{Conclusions}

1. The uniform refinement of prior austenite grain can increase the density of packet boundary and block boundary, so as to obtain a higher density of HAGBs and realize multi-level microstructure refinement.

2. The contribution of this microstructure refinement formed by refining prior austenite grains to toughness is significant, but its contributions to strength and elongation is relatively limited.

3. If the PAGs are mixed crystal, the new formed block boundaries are fewer, and the density of high angle boundary with misorientation $>45^{\circ}$ will be reduced.

4. Mixed crystal PAGs weaken the positive effect of microstructure refinement on toughness improvement.

Author Contributions: Conceptualization, X.L. and C.S.; methodology, X.L.; software, J.Z.; formal analysis, G.L., Q.W. and J.Z.; investigation, X.L., G.L., Q.W. and Z.X.; resources, Q.W., R.D.K.M. and C.S.; writing-original draft preparation, X.L. and J.Z.; writing-review and editing, G.L., Z.X. and R.D.K.M.; supervision, R.D.K.M. and C.S.; funding acquisition, Q.W. and C.S. All authors have read and agreed to the published version of the manuscript.

Funding: This research is funded by Key Research and Development Program of Shandong Province, China (2019JZZY020238).

Institutional Review Board Statement: Not applicable.

Informed Consent Statement: Not applicable.

Data Availability Statement: Not applicable.

Acknowledgments: Thanks are due to Shuai Su for providing experimental steels in this study.

Conflicts of Interest: The authors declare no conflict of interest. 


\section{References}

1. Morito, S.; Tanaka, H.; Konishi, R.; Furuhara, T.; Maki, T. The Morphology and Crystallography of Lath Martensite in Fe-C Alloys. Acta Mater. 2003, 51, 1789-1799. [CrossRef]

2. Zhao, J.; Li, X.; Wang, X.; Liu, S.; Shang, C. Distribution Feature of Specific Misorientation Angle in a Bainitic Steel. Mater. Charact. 2021, 172, 110874. [CrossRef]

3. Guo, Z.; Lee, C.; Morris, J. On Coherent Transformations in Steel. Acta Mater. 2004, 52, 5511-5518. [CrossRef]

4. Liu, D.; Luo, M.; Cheng, B.; Cao, R.; Chen, J. Microstructural Evolution and Ductile-to-Brittle Transition in a Low-Carbon MnCrMoNiCu Heavy Plate Steel. Met. Mater. Trans. A 2018, 49, 4918-4936. [CrossRef]

5. Lambert-Perlade, A.; Gourgues, A.F.; Pineau, A. Austenite to Bainite Phase Transformation in the Heat-Affected Zone of a High Strength Low Alloy Stee. Acta Mater. 2004, 52, 2337-2348. [CrossRef]

6. Bouyne, E.; Flower, H.; Lindley, T.; Pineau, A. Use of EBSD Technique to Examine Microstructure and Cracking in a Bainitic Steel. Scr. Mater. 1998, 39, 295-300. [CrossRef]

7. Li, X.; Zhao, J.; Cong, J.; Misra, R.; Wang, X.; Shang, C. Machine Learning Guided Automatic Recognition of Crystal Boundaries in Bainitic/Martensitic Alloy and Relationship between Boundary Types and Ductile-to-Brittle Transition Behavior. J. Mater. Sci. Technol. 2021, 84, 49-58. [CrossRef]

8. Miao, C.L.; Shang, C.J.; Zhang, G.D.; Subramanian, S.V. Recrystallization and Strain Accumulation Behaviors of High Nb-Bearing Line Pipe Steel in Plate and Strip Rolling. Mater. Sci. Eng. A 2010, 527, 4985-4992. [CrossRef]

9. Hwang, B.; Kim, Y.G.; Lee, S.; Kim, Y.M.; Kim, N.J.; Yoo, J.Y. Effective Grain Size and Charpy Impact Properties of High-Toughness X70 Pipeline Steels. Met. Mater. Trans. A 2005, 36, 2107-2114. [CrossRef]

10. Miao, C.; Shang, C.; Wang, X.; Zhang, L.; Subramanian, M. Microstructure and Toughness of HAZ in X80 Pipeline Steel with High $\mathrm{Nb}$ Content. Acta Met. Sin. 2010, 46, 541-546. [CrossRef]

11. You, Y.; Shang, C.; Wenjin, N.; Subramanian, S. Investigation on the Microstructure and Toughness of Coarse Grained Heat Affected Zone in X-100 Multi-Phase Pipeline Steel with High Nb Content. Mater. Sci. Eng. A 2012, 558, 692-701. [CrossRef]

12. Gourgues, A.-F.; Flower, H.M.; Lindley, T.C. Electron Backscattering Diffraction Study of Acicular Ferrite, Bainite, and Martensite Steel Microstructures. Mater. Sci. Technol. 2000, 16, 26-40. [CrossRef]

13. Karmakar, A.; Kundu, S.; Roy, S.; Neogy, S.; Srivastava, D.; Chakrabarti, D. Effect of Microalloying Elements on Austenite Grain Growth in $\mathrm{Nb}-\mathrm{Ti}$ and $\mathrm{Nb}-\mathrm{V}$ Steels. Mater. Sci. Technol. 2014, 30, 653-664. [CrossRef]

14. Adrian, H. Thermodynamic Model for Precipitation of Carbonitrides in High Strength Low Alloy Steels Containing up to Three Microalloying Elements with or without Additions of Aluminium. Mater. Sci. Technol. 1992, 8, 406-420. [CrossRef]

15. Wang, C.F.; Wang, M.Q.; Shi, J.; Hui, W.J.; Dong, H. Effect of microstructural refinement on the toughness of low carbon martensitic steel. Scr. Mater. 2008, 58, 492-495. [CrossRef]

16. Wang, C.F.; Wang, M.Q.; Shi, J.; Hui, W.J.; Dong, H. Microstructural Characterization and Its Effect on Strength of Low Carbon Martensitic Steel. J. Mater. Sci. Technol. 2007, 23, 659-664.

17. Tomita, Y.; Okabayash, K. Effect of Microstructure on Strength and Toughness of Heat-Treated Low Alloy Structural Steels. Metall. Trans. A 1986, 17, 1203-1209. [CrossRef]

18. Morito, S.; Yoshida, H.; Maki, T.; Huang, X. Effect of Block Size on the Strength of Lath Martensite in Low Carbon Steels. Mater. Sci. Eng. A 2006, 438-440, 237-240. [CrossRef]

19. Luo, Z.-J.; Shen, J.-C.; Su, H.; Ding, Y.-H.; Yang, C.-F.; Zhu, X. Effect of Substructure on Toughness of Lath Martensite/Bainite Mixed Structure in Low-Carbon Steels. J. Iron Steel Res. Int. 2010, 17, 40-48. [CrossRef]

20. Long, S.L.; Liang, Y.L.; Jiang, Y.; Liang, Y.; Yang, M.; Yi, Y.L. Effect of Quenching Temperature on Martensite Multi-Level Microstructures and Properties of Strength and Toughness in 20CrNi2Mo Steel. Mater. Sci. Eng. A 2016, 676, 38-47. [CrossRef]

21. Liu, M.; Shi, B.; Wang, C.; Ji, S.; Cai, X.; Song, H. Normal Hall-Petch Behavior of Mild Steel with Submicron Grains. Mater. Lett. 2003, 57, 2798-2802. [CrossRef]

22. Yang, H.-S.; Bhadeshia, H. Austenite Grain Size and the Martensite-Start Temperature. Scr. Mater. 2009, 60, 493-495. [CrossRef]

23. Kim, M.-C.; Oh, Y.J.; Hong, J.H. Characterization of Boundaries and Determination of Effective Grain Size in Mn-Mo-Ni Low Alloy Steel from the View of Misorientation. Scr. Mater. 2000, 43, 205-211. [CrossRef]

24. Li, X.; Zhao, J.; Wang, J.; Wang, X.; Liu, S.; Shang, C. Effect of Boundaries on Toughness in High-Strength Low-Alloy Steels from the View of Crystallographic Misorientation. Mater. Lett. 2019, 259, 126841. [CrossRef] 